\title{
CHANGE EQUATION EFFECTIVENESS: EMPIRICAL EVIDENCE FROM SOUTH-EAST EUROPE
}

\author{
Mladen Čudanov, Vesna Tornjanski, Ondrej Jaško
}

\section{Introduction}

Today's highly volatile business environment has initiated a wide variety of changes within organizations of all industries (Hurn, 2012). Change dynamics, in general, is likely to increase in organizational context due to:

- Digital and innovation disruption;

- Shifting social and demographic trends;

- Growing knowledge-based economy and knowledge workforce development;

- More sophisticated customer needs; and

- Global economic integration and liberalization.

Regardless of its root-cause, it has been argued that change occurs in various shapes, forms and intensity (Jarrett, 2008). Accordingly, many authors recognize that key factor of an organization's effectiveness lie in the ability to adapt to ever-present change (Brisson-Banks, 2010), while successful change management became a pattern for organizational survival and long-term sustainability (Todnem, 2005; Cudanov et al., 2012a; Cameron \& Green, 2015; Jeraj et al., 2015; Al-Haddad \& Kotnour, 2015).

Despite growing tendency of organizational changes and its significant role in today's highly volatile and continuously evolving business environment, the evidence shows low change success rate. According to the Druckman and Bjork (1991), more than $60 \%$ of organizational change strategies are deserted quickly. Beer and Nohria (2000) reported a high failure rate of all change initiatives amounting to around $70 \%$. Smith (2002) analyzed 49 studies that dealt with success rates of various types of organizational changes. Based on the reported results, it has been found that strategy deployment has the highest success rate with the $58 \%$, while the lowest success rate of $19 \%$ refers to cultural change. It has been noted that at least $40 \%$ of all organizational change efforts consist of simultaneous different types of changes (Smith, 2002).

Burnes (2004) noted that low change success rate lies in the fundamental deficiency of appropriate framework for managing and implementing an organizational change, along with a variety of contrary theories and approaches that often lack empirical evidence. Another perspective on this issue points out that change fails due to the high presence of resistance to change of both managers and employees (Washington \& Hacker, 2005). Recently, it has been argued that low change success rate represents an outcome of low commitment to change and insufficient change planning activities (Al-Haddad \& Kotnour, 2015). Adizes et al. (2017) have found a very low match between perception of timing for consultant engagement and their actual engagement, which can also explain failure.

On the other hand, it has been argued that Beckhard and Harris (1977; 1987) change equation is widely accepted model, used to effectively support actions towards powerful and successful change (Holman et al., 2007). The model emphasizes that for change to occur, dissatisfaction with the status quo, compelling vision and practical first steps have to be simultaneously higher than resistance to change (Beckhard \& Harris, 1977; 1987). However, this assertion is not supported by empirical results from change management practice. Dannemiller and Jacobs (1992) stated that the model is more conceptual rather than practical.

The complexities of the change process and uncertainties of change outcome impose large amount of risk of appropriate decisions, which further can result in irreparable effects. Accordingly, there is a need for development and adoption of decision-making ecosystem in change management practices to prevent 
undesirable outcomes. In other words, there is a growing urgency for integration of appropriate tools and software packages with logical and systematic approaches that include both external and internal factors, feasible alternatives before and during managing change process (Wood \& Bandura, 1989; Tornjanski et al., 2014) to add value on final change expectations.

With that in mind, the purpose of this paper is twofold. The study aims to shed light on the validity of change equation model based on empirical research on one side and to introduce quantitative decision-making model in organizational change management practices, on the other. We intend to provide a reliable framework as the basis for effective decisionmaking in the area of change management and to enable increasing success of change outcome towards sustainable change management.

\section{Literature Review}

The change equation may be regarded as an important turning point for organizational development theory since it represents a significant shift in thinking of managing change from conservative Taylor's "control-andcommand" model to the model that involve all employees in a change process. This approach lowers barriers between employees and managers within an organization as a result of changes in organizational design over the time (Beer \& Walton, 1987). Young (2009) sees change equation as a system approach to organizational change, while Cameron and Green (2015) suggest that Beckhard and Harris change formula can be useful method when approaching the restructuring process.

In the international context, existing literature on the subject of change equation application in real-life practice is mostly based on a qualitative, not quantitative application of the concept. For example, Cady et al. (2014) presented a successful application of change equation based on case studies of information technology service in South Africa and international retailer that had the aim to develop business in Europe, showing its practical value that brought valuable results to companies that followed change equation approach during the change process. Similarly, Murphy (2016) demonstrated a strategy to overcome resistance to change in schools based on based on change formula case example. On the quantitative side,
Chavez (2011) examined a correlation of status quo bias in managers, using components of change equation as independent variables in the study that consisted of 79 participants from two newspaper organizations based in the USA. Although the overall research is founded on Beckhard and Harris change model, its application did not follow basic principles of change equation but rather took into account its components to test the hypotheses.

\subsection{The Change Equation Development}

Looking back into history, the change equation was developed in the early 1960s. The initial creator of the first generation of the change equation was David Gleicher, whose idea was published for the first time by Beckhard (1975) in the form of equation (1). Two years later, the equation (strictly speaking in the form of inequality) was also issued in the publication of Beckhard and Harris (1977) with attribution to David Gleicher.

$$
C=(A B D)>X
$$

Where:

- "C" refers to change,

- "A" attributes to the degree of dissatisfaction with the status quo,

- "B" equals to the clear desired state of the future,

- "D" defines practical first steps towards the desired state, and

- " $X$ " represents cost of the change in the equation (Beckhard, 1975; Beckhard \& Harris, 1977; Cady et al., 2014; Cameron \& Green, 2015).

Ten years later, Beckhard and Harris (1987) presented the revised change equation by replacing costs $(X)$ with the resistance to change $(R)$, and by reframing $A, B$ and $D$ components aiming at more practical applications. Dannemiller and Jacobs (1992) have continued to work on the equation development by setting variables in mnemonics (Cady et al., 2014). This paper focuses on the second generation of the change equation, referring to Beckhard and Harris (1987) publication.

The change equation is built upon a temporal and three general phases of the rational planning of organizational change: understanding the actual state, recognition of the future state and designing a transition state. A transition is viewed as a disordered phase 
that shifts organization from one condition of illusive-stable equilibrium to another (Lewin, 1964; Beckhard \& Harris, 1987; Kempster et al., 2014). Bridges (1991) noted that organizational change models require the inclusion of transitions in change plans to enhance the possibility of change success (Brisson-Banks, 2010). Beckhard and Harris (1977) argue that the transition phase is crucial for the sake of future state quality, which is considerably influenced by this stage. According to the authors, almost every large-scale change can be perceived as a transition, irrelevant of its type and content (Beckhard \& Harris, 1977; Nadler, 1981). Beckhard and Harris (1977; 1987) hypothesize that four elements have to be in place simultaneously for change to occur. Such assumption is based on the change equation components that should be taken into account to effect real change (Beckhard \& Harris, 1987).

\subsection{The Change Equation Components}

Beckhard and Harris change model synthesizes four components, as shown in Equation (2).

$$
C=D^{*} V^{*} F>R
$$

The first factor, "D", refers to the degree of dissatisfaction with the status quo, in contrast to the variable " $D$ " in Equation 1. Chiaburu and Baker (2006) in their research, carried out in the USA, have found that personal-related factors including ideology sharing between employees, interactions between peers and propensity to trust, call for taking an "extra-role behavior" towards challenging the status-quo in employees. Authors also found that output control by employees' supervisor represents important predictor that challenges the status quo.

Dissatisfaction with the status quo in Beckhard and Harris's change model illustrates discontent of employees with the actual situation, noting that employees would not be motivated to change if they are satisfied with the current situation (Beckhard \& Harris, 1987). High level of dissatisfaction with the status quo represents a significant factor that contributes to reducing the level of resistance to change (Beckhard \& Harris, 1987). Similarly, Ford and Ford (1994) change model takes into account dissatisfaction with the status quo as a fundamental element for change to occur (Eisenbach et al., 1999). Equivalently, Kotter
(1996) and Johnson (2004) have recognized that presence of dissatisfaction with the status quo is one of the components that should be thoughtfully considered in managing change efforts.

The second component, "V", relates to the compelling vision in the change process. Vision should be attractive, understandable, aimable and shared in details with all employees with the purpose to bring employees positive attitude for a future state to move forward (Beckhard \& Harris, 1987). Pearce and Ensley (2004, p. 260,261$)$ described shared vision "as a common mental model of the future state of the team or its tasks that provides the basis for action within the team". Kouzes and Posner (1988) stated that leaders should not be necessarily dissatisfied, but instead should provide an attractive and engaging vision of a future. Beckhard and Harris (1987) argue that positive vision of the future lowers resistance to change and increases possibilities for change to occur. Development of vision and involvement of employees in the change process have been recognized by Kanter et al. (1992) as integral elements against resistance to change. Furthermore, Kotter's (1996) and Luecke's (2003) change models propose creation of shared vision as one of the key steps in effective change management. McAdam (2003) has noted that vision is one of the key factors in radical change process that contributes to overall organizational development. Haque et al. (2016) in their recent research conducted in Southern California have found that vision influences organizational growth through mediating effects of organizational readiness for change.

The third component, "F", characterizes practical first steps or worthwhile actions as the beginning of a change process towards the preferred future state. The significance of the actions can be explained by the notion "Vision without action is a dream" (Higgs \& Dulewicz, 2016, p. 80). Accordingly, Beckhard and Harris (1987) have recognized that first actions steps correspond to fundamentals in the process of materializing the vision. Moreover, it has been acknowledged that engagement of employees in this process implies more effective way towards achieving the vision. In other words, it has been positing that when employees participate in actions design with the possibilities to express their views on plan scheme, change dynamics, 
situation or processes, often results in positive feelings that support actionable change and therefore increases possibilities of change success (Beckhard \& Harris, 1977; 1987).

The fourth component, "R", applies to resistance to change. Resistance to change has been found as the biggest limitation to successful change (Al-Haddad \& Kotnour, 2015). An extensive literature suggests that the organizational culture represents a primary source of resistance and significant threat to organizational change efforts (Latta, 2015). Bovey and Hede (2001) have empirically examined resistance to organizational change in nine organizations that implemented major changes in Australia. According to research results, individuals' irrational ideas correlate with behavioral tendency to resist change. Erwin and Garman (2010) have analyzed 18 articles with reported study results regarding to resistance to change. Analyzed articles contain diverse types of changes, organizations and regions, including Europe, Australia, Africa and North America, based on which extensive practical guidance is carried out, by taking into account affective, cognitive and behavioral perspectives of resistance to change, yet individual biases towards resistance or openness, individual understanding, communication, participation and trust in management and its style. When existing change models are in question, it has been recognized that only two models, i.e. Predişcan change model and John Sena change model contain phases that directly deal with the resistance to change reduction. On the other hand, Edgar Huse change model, Kotter's change model, Tichy and Devanna change model, Nadler and Tushman change model and Price Waterhouse Change Integration Team model indirectly act on the resistance to change mitigation (Braduţanu, 2012).

The multiplication of $\mathrm{D}, \mathrm{V}$ and $\mathrm{F}$ elements of the change equation signifies that if any of the elements is zero or near to zero, the outcome will also be zero or near to zero, notably reducing probability for change to occur. In other words, low values of $D, V$ and $F$ elements do not reimburse each other. For change success, $D, V$ and $F$ need to have synergistically higher weights than $R$.

Accordingly, our general hypothesis is that change will be successful if multiplied dissatisfaction, compelling vision of preferred future and clear first steps towards the desired occurrence are higher than resistance to change, and vice versa.

More specifically:

H1: Organizational change success significantly differs between two groups, i.e. those that recognize successful change according to the change equation (The term: change equation is used in the form of inequality.) $D^{*} V^{*} F-R \geq 0$ and those that recognize unsuccessful (failed) change according to the change equation $D^{*} V^{*} F-R<0$.

H2: There is negative relationship between $D^{*} V^{*} F$ and $R$, and there is positive correlation between $D^{*} V^{*} F>R$ and change success variable in the model.

H3: The change equation can successfully predict change success and explain a portion of change success variability.

\section{Research Methods}

\subsection{Survey Method and Survey Instrument}

To test the validity of the change equation and its practical effectiveness, primary data were collected using a survey method. Based on the broader literature review (e.g. Bovey \& Hede, 2001; Haque et al., 2016; Holt et al., 2007; Jones et al., 2005; Wu \& Wu, 2016), a web-based questionnaire with a five-point scale is employed as a survey instrument. During the survey development, all required methodological principles were met (Saris \& Gallhofer, 2014).

Questionnaire contains 43 questions that are grouped into seven main sections: (a) Personal information of respondents with regard to gender, age, education, position at a company, years of overall and current work experience; (b) Information about company in which respondent is employed by, i.e. industry per business type, company size; (c) Third group of questions refers to the level of influence of external and internal factors on change initiation. Further parts of the questionnaire are designed with the aim to obtain necessary understanding of actual, future and transition states, based on which change equation is built. More specifically, (d) Fourth section refers to measurement of the degree of (dis)satisfaction and resistance to change; (e) Followed by measurement of the clarity and strength of the vision of change; (f) Next set of questions refers to change implementation phase and measurement of the clarity of actions towards 
preferred future state; (g) Final set of inquiries appertain to assessment of effectiveness of implemented change, i.e. the degree of change success, using 12 variables to measure the phenomenon.

To prevent careless responses, a control question was embedded in the questionnaire and conflicting answers were finally eliminated from further analysis, with the aim to obtain reliable and accurate output.

The Questionnaire is available at: https://docs.google.com/forms/d/e/1FAlpQLSc 93PWqwrkHm7xeJ4iVknNWZdDzW2rOOgxE sKMxIOLuRMkvkw/viewform for all interested academics and practionnaires who would like to participate in future research on this subject.

\subsection{Data Collection}

Sampling frame includes employees in different industries in South-East Europe who have faced any type of organizational change. Respondents from Serbia, Montenegro, Romania, Croatia, Greece, Macedonia, Bosnia and Hercegovina and Slovenia were asked to answer all questions based on their perception of a situation which initiated a change in an organization they are employed. The questionnaire was distributed to respondents in the national language for contributors from Serbia, Montenegro, Croatia, Bosnia and Hercegovina, while questionnaire in the English language was shared to participants from Romania, Greece, Macedonia and Slovenia. To take advantage of objective responses, the questionnaire specified that it was entirely used for research purposes and granted respondents confidentiality. Questionnaires were completed by submitting the form on the given web page. To prevent unauthorized participants in the research study, e-mail address was a mandatory field that was reconciled in the phase of results analysis. No unauthorized respondents were found.

A pre-test was carried out through a questionnaire survey of 10 volunteers from different industries in South-East Europe. The questionnaire was subsequently revised to eliminate any ambiguities, according to the suggestions obtained in the pilot survey. A webbased questionnaire was sent via e-mail to 150 potential respondents, and 86 respondents from 14 different industries have completed the questionnaire, yielding a response rate of $57.33 \%$. Of the total number of respondents who have completed questionnaire, five were excluded from further analysis due to conflicting control question answers. Although the sample is relatively small, reliability and accuracy are increased because authors were qualitatively familiar with organizational changes in those organizations, so research data go beyond simple anonymous survey.

\subsection{Data Analysis}

Data were analyzed in three main phases using SPSS software package. The first phase of data analysis encompasses scale reliability test using Cronbach's Alpha (George \& Mallery, 2003). The second phase of data analysis provides an insight into the distribution of participants per industries under the study utilizing frequencies, followed by distribution normality assessment using KolmogorovSmirnov test and $Q Q$ plots. The final phase of data analysis implies hypotheses testing. To this end, the advantages of t-test were used to determine statistically significant differences between two groups. It has been argued that t-test is an appropriate analysis tool when dealing with relatively small samples of data (Krishnaswamy et al., 2006, p. 352). The authors have assumed that data are presented in the interval scale, given that variables are calculated as an average construct comprised of five-point Likert scale items (McCall, 2001). Further, correlation analysis is utilized to estimate the strength of relationship between corresponding elements of the model. More specifically, Pearson's correlation coefficient is employed to validate the association between variables (Krishnaswamy et al., 2006). Finally, to predict the value of an outcome, linear regression analysis is exploited based on predictor variables, following prescribed fundamentals outlined in the methodological guidelines reported by Saunders et al. (2011).

\section{Results}

The first phase of data analysis refers to scale reliability test. Internal consistency of the scale validity was analyzed using Cronbach's Alpha test. Each analyzed variable is calculated as a sum of Likert-scale items with the same direction and whose number is shown in the column "Items" of the respective table.

The results of Cronbach's Alpha, depicted in Tab. 1, indicate a high level of internal consistency for the following set of variables: 


\section{Tab. 1: Results of internal consistency analysis}

\begin{tabular}{c|l|c|c} 
Variable & \multicolumn{1}{|c|}{ Variable description } & Cronbach's Alpha & Items \\
\hline D & The degree of dissatisfaction with the status quo & 0.872 & 3 \\
\hline V & Clarity and strength of vision of change & 0.824 & 3 \\
\hline F & Clarity of actions towards preferred future state & 0.874 & 3 \\
\hline R & Resistance to change & 0.620 & 4 \\
\hline C & Change success & 0.871 & 12 \\
\hline
\end{tabular}

the degree of dissatisfaction with the status quo $(\alpha=0.872)$, clarity and strength of vision of change $(\alpha=0.824)$, clarity of actions towards preferred future state $(\alpha=0.874)$ and change success $(\alpha=0.871)$. The lowest Cronbach's Alpha coefficient refers to $R$ variables $(\alpha=0.620)$.

The second phase of data analysis encompasses frequencies per industry, according to the distribution of participants included in the study. Financial industry counts the highest number of respondents $(45 \%)$, followed by IT industry (15\%), education $(7 \%)$, food manufacturing industry $(6 \%)$, creative industry $(5 \%)$, tourism and hospitality $(3 \%)$, textiles and leather $(3 \%)$, construction industry $(3 \%)$, health care $(2 \%)$, trade in goods $(2 \%)$, traffic industry $(2 \%)$, chemical and pharmaceutical industry $(2 \%)$ and energy industry $(2 \%)$.

Concerning the distribution normality evaluation, the results of multiplied average values of $D, V$ and $F$ variables, i.e. $D^{*} V^{*} F$, indicate a normal distribution with the mean value of 0.379 and standard deviation of 0.25 . Further, the results of a normal distribution of the attribute $R$, i.e. resistance to change show normality on the edge of confirmation with the significance of 0.048 , taking into account mean value of 0.462 and standard deviation of 0.15 . However, the $Q Q$ plot clearly depicts normal distribution. Regarding variables that measure $C$, i.e. change success, the results demonstrate normal distribution having the mean value of 0.667 and standard deviation of 0.16 . Finally, normal distribution of the synthesized model, i.e. $D^{*} V * F>R$ is confirmed with the mean of 0.082 and standard deviation of 0.36 . The results are statistically significant.

Taking into account previously shown results, further analysis for hypothesis testing includes parametric methods consisting of independent samples t-test and Pearson's correlation. The results of independent t-test are presented in Tabs. 2 and 3, respectively.

To test hypothesis 1 , an independent samples t-test was carried out to compare the normalized change success variable means between the two groups of respondents in respect to the Beckhard and Harris change model. Respondents were divided into two groups: first group consists of respondents who recognized successful change according to the equation: DVF $-R \geq 0$. Second group

\section{Tab. 2: T-test group statistics results}

\begin{tabular}{l|c|c|c|c|c} 
& DVF-R & $\mathbf{N}^{*}$ & Mean & Std. Deviation & Std. Error Mean \\
\hline \multirow{2}{*}{$\begin{array}{l}\text { Normalized Change } \\
\text { Success }\end{array}$} & $\geq 0$ & 31 & 0.7500 & 0.1425 & 0.0256 \\
\cline { 2 - 6 } & $<0$ & 50 & 0.6143 & 0.1533 & 0.0217 \\
\hline
\end{tabular}


Tab. 3: Independent samples test results

\begin{tabular}{|c|c|c|c|c|c|c|c|c|c|}
\hline \multirow{3}{*}{$\begin{array}{l}\text { Normalized } \\
\text { change } \\
\text { success } \\
\text { mean test }\end{array}$} & \multicolumn{2}{|c|}{$\begin{array}{l}\text { Levene's Test } \\
\text { for Equality of } \\
\text { Variances }\end{array}$} & \multicolumn{7}{|c|}{ t-test for Equality of Means } \\
\hline & \multirow[t]{2}{*}{$\mathrm{F}$} & \multirow[t]{2}{*}{ Sig. } & \multirow[t]{2}{*}{$\mathrm{t}$} & \multirow[t]{2}{*}{ df } & \multirow[t]{2}{*}{$\begin{array}{c}\text { Sig. } \\
\text { (2-tailed) }\end{array}$} & \multirow[t]{2}{*}{$\begin{array}{c}\text { Mean } \\
\text { Difference }\end{array}$} & \multirow[t]{2}{*}{$\begin{array}{l}\text { Std. Error } \\
\text { Difference }\end{array}$} & \multicolumn{2}{|c|}{$\begin{array}{l}95 \% \text { Confidence } \\
\text { Interval of the } \\
\text { Difference }\end{array}$} \\
\hline & & & & & & & & Lower & Upper \\
\hline $\begin{array}{l}\text { Equal } \\
\text { variances } \\
\text { assumed }\end{array}$ & 0.493 & 0.485 & 3.976 & 79 & 0.000 & 0.1357 & 0.0341 & 0.0678 & 0.2036 \\
\hline
\end{tabular}

Source: own

of respondents implies unsuccessful change according to the equation: DVF $-\mathrm{R}<0$. Based on the obtained results shown in Tab. 2, successful change counts $38.27 \%$ of the total number of respondents $(0.75 \pm 0.14)$. On the other hand, $61.73 \%$ participants recognized unsuccessful change $(0.61 \pm 0.15)$.

Tab. 3 provides insight into the independent samples t-test results, based on which the model is verified. High values of $t$ statistics indicate that there is less than $0.1 \%$ probability that difference between groups occurred due to chance. The results are statistically significant.

Levene's test for equality of variances $(F=0.493 ; p>0.05)$ shows that the variance of normalized change success in regard to $D^{*} V^{*} F-R$. Based on the results of t-test for equality of means $(t=3.98 ; p<0.05)$, there is evidence that $D^{*} V * F-R$ has the significant effect on change success at the alpha $=0.00$ level. Therefore, hypothesis 1 is supported.

Hypothesis 2 is tested by examining the strength of the relationship between variables using Pearson's correlation analysis. The results are depicted in Tab. 4.

According to the results, the multiplication of $D, V$ and $F$ variables are in downhill relationship with $R$ variable $(r=-0.551 ; p<0.01)$. If we take into account normalized multiplied model consisting of $\mathrm{D}, \mathrm{V}, \mathrm{F}$ and decreased $\mathrm{R}$ in one hand and $\mathrm{C}$ - referring to change success in other, then the results indicate moderate positive association between the two $(r=0.545$; $p<0.01$ ). The results are statistically significant. Hypothesis 2 is supported.

Next step in verifying the model refers to testing the hypothesis 3. Regression analysis aims at predicting the value of change effectiveness, i.e. change success as a dependent variable from $D^{*} V^{*} F-R$ as an independent variable. Tab. 5 presents summary of linear regression model 1 explained by Equation 3.

$$
C=\alpha+\beta(D V F-R)+\varepsilon
$$

\section{Tab. 4: The results of Pearson's correlation analysis for selected variables}

\begin{tabular}{l|c|c|c|c} 
& $\mathbf{D}^{*} \mathbf{V}^{*} \mathbf{F}$ & $\mathbf{R}$ & $\mathbf{D}^{*} \mathbf{V}^{*} \mathbf{F}-\mathbf{R}$ & Normalized C \\
\hline $\mathrm{D}^{*} \mathrm{~V}^{*} \mathrm{~F}$ & 1 & $-0.551^{* *}$ & $0.934^{* *}$ & $0.529^{* *}$ \\
\hline $\mathrm{R}$ & $-0.551^{* *}$ & 1 & $-0.812^{* *}$ & $-0.410^{* *}$ \\
\hline $\mathrm{D}^{*} \mathrm{~V}^{*} \mathrm{~F}-\mathrm{R}$ & $0.934^{* *}$ & $-0.812^{* *}$ & 1 & $0.545^{* *}$ \\
\hline Normalized C & $0.529^{* *}$ & $-0.410^{* *}$ & $0.545^{* *}$ & 1 \\
\hline
\end{tabular}




\section{Tab. 5: Linear regression model 1 summary}

\begin{tabular}{c|c|c|c|c} 
Model & $\mathbf{R}$ & $\mathbf{R}^{\mathbf{2}}$ & Adjusted $\mathbf{R}^{\mathbf{2}}$ & Std. Error of the Estimate \\
\hline 1 & $0.545^{\mathrm{a}}$ & 0.297 & 0.288 & 0.1371 \\
\hline
\end{tabular}

Source: own

\section{Tab. 6: Coefficients of linear regression for $D^{*} V^{*} F-R$ variable}

\begin{tabular}{|c|c|c|c|c|c|c|}
\hline & \multirow[t]{2}{*}{ Model } & \multicolumn{2}{|c|}{$\begin{array}{l}\text { Unstandardized } \\
\text { Coefficients }\end{array}$} & \multirow{2}{*}{$\begin{array}{c}\text { Standardized } \\
\text { Coefficients } \\
\text { Beta } \\
\end{array}$} & \multirow[t]{2}{*}{$\mathbf{t}$} & \multirow[t]{2}{*}{ Sig. } \\
\hline & & B & Std. Error & & & \\
\hline \multirow{2}{*}{1} & (Constant) & 0.687 & 0.016 & & 430.899 & 0.000 \\
\hline & $D^{*} V^{*} F-R$ & 0.249 & 0.043 & 0.545 & 50.774 & 0.000 \\
\hline
\end{tabular}

Source: own

Based on the output presented in Tab. 5 $\left(R^{2}=0.297 ; R^{2}\right.$ adj. $\left.=0.288\right), 29.7 \%$ of change success is explained by $D^{*} V^{*} F-R$.

Tab. 6 shows the results of coefficients of linear regression using ANOVA analysis. For the purpose of the hypotheses 3 testing, variable $D^{*} V^{*} F-R$ is considered a constant variable.

ANOVA analysis has resulted in $\mathrm{F}$ statistics of 33.342, with significance $p<0.001$, meaning that formula $D^{*} V^{*} F-R$ statistically significantly predicts change success. Coefficients are obtained using the Equation 4.

$$
C=0.648+0.297(D V F-R)
$$

Following figures support the results acquired from the linear regression model, taking into account that key preconditions for the regression model were satisfied. The results are depicted in Figs. 1 and 2.

\section{Fig. 1: Distribution of residuals and homoscedasticity}

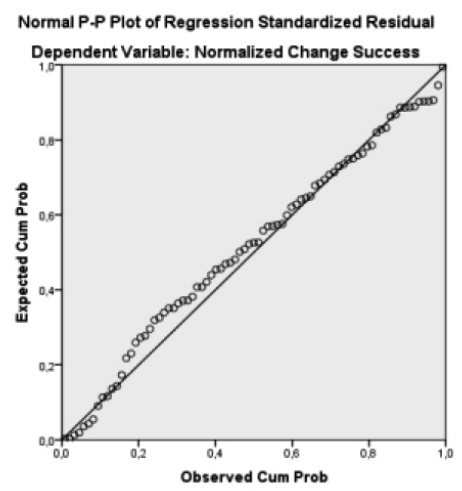




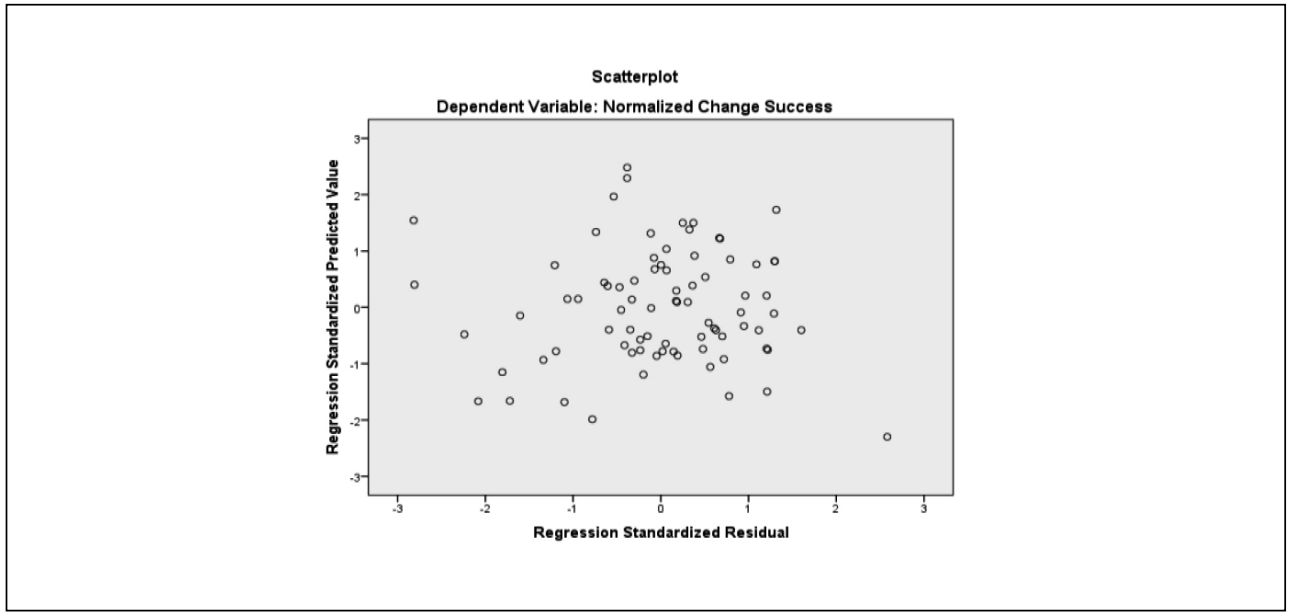

Source: own

The results displayed in Figs. 1 and 2 certify that linear relationship is present with no significant outliers. Moreover, observations for independent and homoscedasticity exist. At the same time, residuals are normally distributed. Based on the obtained results, there is enough evidence to confirm that change equation can successfully explain part of the variability of change success, enough to be practically applicable. Accordingly, hypothesis 3 is partially supported, with formula explaining $29.7 \%$ of variability.

\section{Discussion and Implications of the Study}

Change management has a vital role in today's highly dynamic business environment. Despite its significance, the evidence shows low change success rate. On the other hand, change equation is recognized as an effective tool in change management practice among practitioners worldwide. Also, the phenomenon is dominant in the research field, taking into account Beckhard and Harris's reference received more than 1,500 citations. Besides, the work of Beckhard and Harris has inspired further researches like Armenakis et al. (1993) who have been cited more than 1,300 times. Finally, change equation plays an important role in education and theory as a core part of organizational theory and change textbooks. However, it is notable that there is no quantitative empirical confirmation of the phenomenon so far.

This study provides an insight into the empirical results of change equation potential to predict successful organizational change and at the same time aims to propose quantitative decision-making model based on change equation application in change management practices to increase change success.

The research was carried out in fourteen different industries. Distinct industries were selected with the aim to obtain more objective insight into the model validity, taking into account different organizational structures, size, cultures and factors that induce change. According to the results, $60 \%$ of respondents participated in the study from industries that are considered as the most dynamic and fastchanging, i.e. financial services and IT industry. On the other hand, a questionnaire was developed to provide flexibility to participants to describe the organizational change which was the subject of further evaluation. Various shapes, forms and intensities of change have added value to this research in respect of model effectiveness, i.e. change success.

Cronbach's Alpha test was employed to measure scale reliability. Following guideline for interpretation of Cronbach's Alpha coefficients, 
which states that values below 0.5 should not be taken into account as acceptable (George \& Mallery, 2003, p. 231), all constructs in this study have acceptable to good external consistency. DeVellis (2003) defines weights between 0.7 and 0.9 as most reliable, and at the same time explain lower coefficients as a result of constructs having fewer items than needed, low inter-relatedness among items or heterogeneous constructs. Based on the obtained results, the lowest Cronbach's Alpha coefficient refers to $R$ variables. We have found that heterogeneous constructs represent the major reason for such outcome. In other words, determination of resistance to change is a subjective assessment based of respondents' behavior, attitudes and beliefs.

The hypotheses were analyzed using proven statistical methods. Based on the results, our general assumption is supported. In other words, successful change occurs when the product of all three variables, i.e. D, $V$ and $F$ is higher than resistance to change, and vice versa. The research results introduced in the study are further discussed regarding implications to the theory and practice.

\subsection{Implications for Theory}

Cameron and Green (2015) noted that Beckhard and Harris change equation can be useful method when approaching the restructuring process. This research extends and deepens such assertion in two essential ways. First, quantitative approach is rarely used in such processes (Cudanov et al., 2012b). Second, a wide variety of described changes were analyzed in this study, which indicates that Beckhard and Harris change equation can be applied not only for restructuring purposes but rather in the broader context of change types.

However, the study reveals weaknesses of the model, based on which specific improvements for its effectiveness were suggested, not discussed in the literature so far. A key issue that was found appertains to measuring $D, V, F$ and $R$ variables. Namely, researcher or practitioner can easily end up on measuring the same phenomenon. Observed separately, the four variables have strong correlations - all coefficients are statistically significant and have absolute values larger than 0.3 , negative for $R$ variable and positive among the rest. High dissatisfaction with status quo, strong vision in change process and appropriate first steps or worthwhile actions as the beginning of organizational change naturally will result in low resistance to organizational change. Following results introduced in the study, it has been found that three principal determinants influence $D, V, F$ and $R$ variables:

- Factors of the organizational change stemming from subjective, personal traits of the participant;

- Factors of the organizational change stemming from the change traits itself;

- Factors of the organizational change stemming from the organizational environment of the participant and change, e.g. organizational culture, peer influence, industrial dynamics, state of the organization.

In order for D, V, F and R not to measure the same phenomenon, construct items for $D$, $V$ and $F$ can focus on subjective interpretation of second and third components (change itself and organizational environment) and $R$ on subjective, personal basis, or general resistance to abstract change of the observed participant. Halo-effect can be a significant problem when measuring these variables, so researchers and practitioners should keep in mind suggestions regarding its influence (Rosenzweig, 2007). In some cases, having $R$ in negative correlation with the multiplied $D, V$ and $F$ variables assume to be the confirmative scenario. If researchers expect negligent responses, $R$ can be used as the control variable. In such case high values of $D, V$ and $F$ are expected to result in low values of $\mathrm{R}$ and vice-versa. Significant deviations from that correlation can be disregarded as inadequate data, especially if supported by statistical analysis of other control questions. Measurement of the variables needs to be applied by multi-item constructs which open the possibility of further quantitative analysis, as in our questionnaire linked in the "2. Research methods" section of this article.

Next, various participants add different contribution to change. Some are more powerful and influential, and if change equation is calculated on a larger sample across the entire organization, then their answers should have different corresponding weights. Stakeholders of organizational change can be roughly divided (Hula, 1999) on key players, like generalists who lead the main effort, specialists who support the change by some scarce resource or knowledge they have and 
"tag-alongs" who just make for the numbers in the change coalition. Generalists should have highest weights, followed by specialists and finally "tag-alongs", our proposal of importance which should be adjusted to each specific situation, is 10,3 and 1 .

Further, normalization of items needs to be very carefully performed, since if $D^{*} V^{*} F$ are not on the same scale with $R$, then the final calculation implies the wrong conclusion. We have experimented, starting from the most obvious standardized z-scores but that produces negative values which do not fit change equation idea. After observing results of several alternatives, we have selected the normalization method demonstrated in Equation 5:

$$
x_{i}^{\prime}=\frac{x_{i}-\min (x)}{\max (x)-\min (x)}
$$

In the formula above $x^{\prime}$ represents the normalized value of any of the used variables $(\mathrm{D}, \mathrm{V}, \mathrm{F}$ and $\mathrm{R}$ ), while the $\mathrm{x}$ represents current, non-normalized value.

\subsection{Implications for Practice}

This study extends and deepens early work on change equation by introducing quantitative decision-making model that can contribute to practitioners in two important ways.

First, research instrument utilized in this study can effectively support measurement of all elements that influence change success in all phases of change management cycles. Having insight into the situation in real time during change process further facilitates effective decision-making and determinates actions towards the successful change outcome. Moreover, research instrument provides enough flexibility to determine the most relevant indicators according to the particular change.

Second, the model can be useful in the post-implementation phase to evaluate change success. Post-implementation evaluation can reveal key indicators that cause change failure, which further facilitates decision-making towards further strategies development for successful outcome.

Finally, quantitative decision-making model based on change equation represents a reliable framework for effective decisions in change management.

\section{Conclusions}

The complexities, uncertainties during managing change process and low change success rate impose growing need for development and adoption of appropriate quantitative approaches, tools and software packages in change management practices to create the value of successful change outcome.

This paper has developed and examined Beckhard and Harris change model, so-called change equation, for the sake of validating its effectiveness in practice. On the other hand, this study was developed with the aim to propose quantitative decision-making model in organizational change management, which is based on change equation application in real time, as an emerging ecosystem that should be further adopted in change management practice to create value in complex decision making and at the same time to increase change success. This study can contribute both to theorists and practitioners in two important ways. First, the paper contributes to the change management theory, business decision-making theory, organizational development theory and the behavioral theory.

Secondly, successful management of change became a pattern for organizational survival and long-term sustainability nowadays. Thus, the selection and properly applied change management model play a significant role in the overall change success outcome. Next, measurement of change success in all phases of change management is of key importance. Change equation can be applicable in all phases of change process, including measurement of the change outcome. Finally, the adoption of corresponding quantitative decision-making model in change management and creating decision-making ecosystem create value by enabling an objective insight into determinants that has to be further developed / re-evaluated to increase change success. Accordingly, the paper contributes to strategic managers, change leaders, change agents and consultants who deal with change management.

Despite its contribution, the study has some limitations that require future research. The first limitation may be found in the regression model results, which show that slightly less than $30 \%$ of the variance of the change success is explained by the model. Consequently, given outcome indicates that remaining $70 \%$ of variance may result of situational factors (e.g. 
organizational size, structure, culture climate, management style, technology), which further may lead to ineffective decision making during managing change process. However, a model that explains $30 \%$ of the variance of the change success in nonlinear and complex business environment cannot be neglected, since "organizational physics" deterministic causeand-effect situations in today's business are rare. This viewpoint is in accordance with the situational theories, as well as with the view there is no unified "silver bullet" approach, emphasizing the view of common business delusions suggested by Rosenzweig (2007).

Next limitation refers to described weaknesses of the model, found in this research, based on which we have summarized recommendations for change equation enhancement that should be further researched:

- Classify the change stakeholders and select a corresponding sample;

- Determine category weights, according to the suggestions provided in this study and consolidate them in respect to the specific situation;

- Measure D, V, F and R using multi-item construct in a questionnaire following given suggestions;

- Normalize variables using the method proposed in the study, or consolidate them by the specific situation;

- Calculate values of the variable $C$ for each cluster of change stakeholders, then ponder it following Equation 6:

$$
C=\sum_{j=1}^{j=n} \sum_{i=1}^{i=m} p_{j}(D V F-R)
$$

C, D, V, F and $\mathrm{R}$ variables represent variables of the change equation, $n$ is the number of categories, $p_{j}$ is the ponder value attributed to the $j$ category of change stakeholders, and $m$ is the number of change stakeholders in $j$ category. Taking into account that scales and ponders have a significant role in the quantitative construction, its adequate selection is important for the entire model effectiveness. Ponder values can be determined in the future research, but it will be specific for each observed organization, with linear relation to the power and hierarchical level of that change stakeholder. For example, in high power distance environment, a lower hierarchical level employee can have the ponder of 1 , while middle manager can have a ponder of 5 , practically meaning that his or her assessment has five times more influence on the organizational change.

\section{References}

Adizes, I., Cudanov, M., \& Rodic, D. (2017). Timing of Proactive Organizational Consulting: Difference between Organizational Perception and Behaviour. Amfiteatru Economic, 19(44), 232-248.

Al-Haddad, S., \& Kotnour, T. (2015). Integrating the organizational change literature: a model for successful change. Journal of Organizational Change Management, 28(2), 234-262. https://dx.doi.org/10.1108/JOCM-112013-0215.

Armenakis, A. A., Harris, S. G., \& Mossholder, K.W. (1993). Creating readiness for organizational change. Human relations, 46(6), 681-703. https://dx.doi.org/10.1177/001872679304600601.

Beckhard, R. (1975). Strategies for large system change. Sloan Management Review, 16(2), 43-55.

Beckhard, R. F., \& Harris, R. T. (1977). Organizational Transitions: Managing complex change. MA: Addison Wesley Publishing Company.

Beckhard, R. F., \& Harris, R. T. (1987). Organizational Transitions: Managing complex change. Reading, MA: Addison-Wesley.

Beer, M., \& Nohria, N. (2000). Cracking the code of change. Harvard Business Review, 78(3), 133-141.

Beer, M., \&Walton,A. E. (1987). Organization change and development. Annual review of psychology, 38(1), 339-367. https://dx.doi. org/10.1146/annurev.ps.38.020187.002011.

Bovey, W. H., \& Hede, A. (2001). Resistance to organizational change: the role of cognitive and affective processes. Leadership \& Organization Development Journal, 22(8), 372-382. https:// dx.doi.org/10.1108/01437730110410099.

Braduţanu, D. (2012). Identifying the Reducing Resistance to Change Phase in an Organizational Change Model. Acta Universitatis Danubius. CEconomica, 8(2), 18-26.

Bridges, W. (1991). Managing Transitions Making the Most of Change. Reading, MA: Addison-Wesley.

Brisson-Banks, C. V. (2010). Managing change and transitions: a comparison of 
different models and their commonalities. Library Management, 31(4/5), 241-252. https://dx.doi.org/10.1108/01435121011046317.

Burnes, B. (2004). Managing Change: A Strategic Approach to Organisational Dynamics (4th ed.). UK: Prentice Hall, Harlow.

Cady, S. H., Jacobs, R., Koller, R., \& Spalding, J. (2014). The Change Formula. OD PRACTITIONER, 46(3), 32-39.

Cameron, E., \& Green, M. (2015). Making sense of change management: a complete guide to the models, tools and techniques of organizational change. London: Kogan Page Publishers.

Chavez, E. (2011). The change equation: A correlation study of status quo bias in managers (Doctoral dissertation, University of Phoenix).

Chiaburu, D. S., \& Baker, V. L. (2006). Extra-role behaviors challenging the statusquo: Validity and antecedents of taking charge behaviors. Journal of Managerial Psychology, 21(7), 620-637. https://dx.doi. org/10.1108/02683940610690178.

Cudanov, M., Jasko, O., \& Savoiu, G. (2012a). Public and public utility enterprises restructuring: Statistical and quantitative aid for ensuring human resource sustainability. Amfiteatru Economic, 14(32), 307-322.

Cudanov, M., Savoiu, G., \& Jaško, O. (2012b). Usage of technology enhanced learning tools and organizational change perception. Computer Science and Information Systems, 9(1), 285-302. https://dx.doi. org/10.2298/CSIS110106043C.

Dannemiller, K. D., \& Jacobs, R. W. (1992). Changing the way organizations change: A revolution of common sense. The Journal of Applied Behavioral Science, 28(4), 480-498. https://dx.doi.org/10.1177/0021886392284003.

DeVellis, R. (2003). Scale development: theory and applications. Thousand Okas: Sage Publications.

Druckman, D., \& Bjork, R. A. (1991). In the Mind's Eye: Enhancing Human Performance. Washington: National Academies Press.

Eisenbach, R., Watson, K., \& Pillai, R. (1999). Transformational leadership in the context of organizational change. Journal of organizational change management, 12(2), 80-89. https://dx.doi.org/10.1108/09534819910263631.

Erwin, D. G., \& Garman, A. N. (2010). Resistance to organizational change: linking research and practice. Leadership \&
Organization Development Journal, 31(1), 39-56. https://dx.doi.org/10.1108/01437731011010371.

Ford, J. D., \& Ford, L. W. (1994). Logics of identity, contradiction, and attraction in change. Academy of Management Review, 19(4), 756-785. https://dx.doi.org/10.2307/258744.

George, D., \& Mallery, P. (2003). SPSS for Windows step by step: A simple guide and reference (4th ed.). Boston: Allyn \& Bacon.

Haque, M. D., TitiAmayah, A., \& Liu, L. (2016). The role of vision in organizational readiness for change and growth. Leadership \& Organization Development Journal, 37(7), 983-999. https://dx.doi.org/10.1108/LODJ-012015-0003.

Higgs, M., \& Dulewicz, V. (2016). Developments in leadership thinking. In Leading with Emotional Intelligence (pp. 75-103). Springer International Publishing. https://dx.doi.org/10.1007/978-3-319-32637-5_6.

Holman, P., Devane, T., \& Cady, S. (2007). The change handbook: The definitive resource on today's best methods for engaging whole systems. San Francisco: Berrett-Koehler Publishers.

Holt, D. T., Armenakis, A. A., Feild, H. S., \& Harris, S. G. (2007). Readiness for organizational change: The systematic development of a scale. The Journal of applied behavioral science, 43(2), 232-255. https://dx.doi.org/10.1177/0021886306295295.

Hula, K. W. (1999). Lobbying together: Interest group coalitions in legislative politics. Washington: Georgetown University Press.

Hurn, B. J. (2012). Management of change in a multinational company. Industrial and commercial training, 44(1), 41-46. https://dx.doi.org/10.1108/00197851211193417.

Jarrett, M. (2008). The new change equation. Business Strategy Review, 19(4), 76-81. https://dx.doi.org/10.1111/j.1467-8616.2008.00567.x.

Jeraj, M., Maric, M., Todorovic, I., Cudanov, M., \& Komazec, S. (2015). The Role of Openness and Entrepreneurial Curiosity in Company's Growth. Amfiteatru Economic, 17(38), 371-389.

Johnson, D. M. (2004). Adaptation of organizational change models to the implementation of quality standard requirements. International Journal of Quality \& Reliability Management, 21(2), 154-174. https://dx.doi.org/10.1108/02656710410516961.

Jones, R. A., Jimmieson, N. L., \& Griffiths, A. (2005). The impact of organizational 
culture and reshaping capabilities on change implementation success: The mediating role of readiness for change. Journal of Management Studies, 42(2), 361-386. https://dx.doi. org/10.1111/j.1467-6486.2005.00500.x.

Kanter, R. M., Stein, B., \& Jick, T. (1992). The Challenge of Organizational Change: How Companies Experience it and Leaders Guide it. New York: Free Press/Maxwell Macmillan International.

Kempster, S., Higgs, M., \& Wuerz, T. (2014). Pilots for change: exploring organisational change through distributed leadership. Leadership \& Organization Development Journal, 35(2), 152-167. https://dx.doi. org/10.1108/LODJ-04-2012-0055.

Kotter, J. P. (1996). Leading change. Boston: Harvard Business School Press.

Kouzes, J., \& Posner, B. (1988). The Leadership Challenge. San Francisco: JosseyBass.

Krishnaswamy, K. N., Sivakumar A. I., \& Mathirajan, M. (2006). Management Research Methodology: Integration of Methods and Techniques. Delhi: Dorling Kindersley.

Latta, G. F. (2015). Modeling the cultural dynamics of resistance and facilitation: Interaction effects in the OC3 model of organizational change. Journal of Organizational Change Management, 28(6), 1013-1037. https://dx.doi.org/10.1108/JOCM-07-2013-0123.

Lewin, K. (1964). Field Theory in Social Science. New York: Harper and Row.

Luecke, R. (2003). Managing change and transition. Boston: Harvard Business School Press.

McAdam, R. (2003). Radical change: a conceptual model for research agendas. Leadership \& Organization Development Journal, 24(4), 226-235. https://dx.doi. org/10.1108/01437730310478093.

McCall, C. H. (2001). An empirical examination of the Likert scale: Some assumptions, development and cautions. In Annual meeting of the CERA Conference (pp. 1-11). South Lake Tahoe, CA.

Murphy, M. (2016). The Tug of War between CHANGE \& RESISTANCE. Educational Leadership, 73(9), 66-70.
Nadler, D. A. (1981). Managing organizational change: An integrative perspective. The Journal of Applied Behavioral Science, 17(2), 191-211. https://dx.doi. org/10.1177/002188638101700205.

Pearce, C. L., \& Ensley, M. D. (2004). A reciprocal and longitudinal investigation of the innovation process: The central role of shared vision in product and process innovation teams (PPITs). Journal of Organizational Behavior, 25(2), 259-278. https://dx.doi.org/10.1002/ job.235.

Rosenzweig, P. (2007). Misunderstanding the nature of company performance: The halo effect and other business delusions. California Management Review, 49(4), 6-20. https://dx.doi.org/10.2307/41166403.

Saris, W. E., \& Gallhofer, I. N. (2014). Design, evaluation, and analysis of questionnaires for survey research (2nd ed.). New York: John Wiley \& Sons.

Saunders, M., Lewis, P., \& Thornhill, A. (2011). Research methods for business students (5th ed.). Harlow: Pearson Education.

Smith, M. E. (2002). Success rates for different types of organizational change. Performance Improvement, 41(1), 26-33. https://dx.doi.org/10.1002/pfi.4140410107.

Todnem By, R. (2005). Organisational change management: A critical review. Journal of change management, 5(4), 369-380. https://dx.doi.org/10.1080/14697010500359250.

Tornjanski, V., Marinković, S., \& Lalić, N. (2014). Application of ANP method based on a BOCR model for decision-making in banking. In Proceedings of the XIV International Symposium SymOrg: New business models and sustainable competetivness (SYMORG 2014). Zlatibor, Serbia.

Washington, M., \& Hacker, M. (2005). Why change fails: knowledge counts. Leadership \& Organization Development Journal, 26(5), 400-411. https://dx.doi. org/10.1108/00251749810232628.

Wood, R., \& Bandura, A. (1989). Impact of conceptions of ability on self-regulatory mechanisms and complex decision making. Journal of personality and social psychology, 56(3), 407-415. https://dx.doi. org/10.1037/0022-3514.56.3.407. 
Wu, C. C. (2016). Status quo bias in information system adoption: a meta-analytic review. Online Information Review, 40(7), 9981017. https://dx.doi.org/10.1108/OIR-09-20150311.

Young, M. (2009). A meta model of change. Journal of Organizational Change Management, 22(5), 524-548. https://dx.doi. org/10.1108/09534810910983488.
Prof. Mladen Čudanov, Ph.D. University of Belgrade Faculty of Organizational Sciences Department of Business Systems Organization

Serbia mladenc@fon.bg.ac.rs

Prof. Ondrej Jaško, Ph.D. University of Belgrade

Faculty of Organizational Sciences Department of Business Systems Organization

Serbia jasko@fon.bg.ac.rs

Vesna Tornjanski, Ph.D. candidate University of Belgrade Faculty of Organizational Sciences Serbia tornjanski401111m@fon.bg.ac.rs 


\title{
Abstract
}

\section{CHANGE EQUATION EFFECTIVENESS: EMPIRICAL EVIDENCE FROM SOUTH-EAST EUROPE}

\author{
Mladen Čudanov, Vesna Tornjanski, Ondrej Jaško
}

This study was developed with the aim to propose quantitative decision-making model in organizational change management, which is based on change equation application in real time, as an emerging ecosystem that should be further adopted in change management practice to create value in complex decision making and at the same time to increase change success. The paper opted for an integrated qualitative and quantitative research methods, based on empirical data collection. Sampling frame includes respondents from fourteen different industries in South-East Europe. Data analyses were carried out in three main phases using proven statistical methods. Based on the results, general hypothesis introduced in the study is supported. In other words, successful change occurs when the product of all three variables, i.e. $D, V$ and $F$ is higher than resistance to change, and vice versa. Also, research results show that change equation can successfully predict change outcome and explain a portion of change success variability. Finally, research findings indicate that the model should be revised and further developed. Research limitations are determined by significant variance in the model that may result of situational factors. Also, the research was based on a relatively limited sample and focused only on data collection from South-East Europe. Despite its limitations, this study can contribute both to theorists and practitioners. First, the paper contributes to the change management theory, business decisionmaking theory, organizational development theory and the behavioral theory. Second, the paper can contribute to strategic managers, change leaders, change agents and consultants who deal with change management by adopting the upgraded change model that can be applied in all phases of change process, including measurement of the change outcome.

Key Words: Beckhard and Harris change model, change equation, quantitative decisionmaking model, change success, organizational change management sustainability.

JEL Classification: C4, C8, LO, O52.

DOI: 10.15240/tul/001/2019-1-007 